\title{
THE INFLUENCE OF BIG FIVE PERSONALITY, COPING STRESS AND DEMOGRAPHIC VARIABLES ON POST TRAUMATIC GROWTH IN ADOLESCENTS
}

\author{
Noffa Iffayanti \\ Noffa.aliffah@gmail.com \\ Anggota HIMPSI Provinsi Jawa Barat
}

\author{
Natris Idriyani \\ natrisidriyani@gmail.com \\ Fakultas Psikologi UIN Syarif \\ Hidayatullah Jakarta
}

\begin{abstract}
This study was conducted to determine the significance of big five personality, coping stress and demographic variables on post traumatic growth in adolescents who lost one parent (Orphans) in five orphanages around Jakarta. Subjects in this study amounted to 232 orphaned teenagers living in orphanages in the Jakarta area, which was taken with nonprobability sampling technique that is purposive sampling. CFA (Confirmatory Factor Analysis) is used to test the validity of measuring instruments and Multiple Regression Analysis is used to test the research hypothesis. The results showed that there was a significant effect together from big five personality, coping stress and demographic variable (gender) to post traumatic growth in adolescent orphanage. Hypothesis test results from big five personality variable dimension show that personality type of openness has a significant influence on post traumatic growth. The results also show the proportion of variance of post traumatic growth described by all independent variables is $9.2 \%$, while the rest is influenced by other variables outside this study.
\end{abstract}

Keywords: post traumatic growth, big five personality, coping stress, gender and adolescent

\begin{abstract}
Abstrak
Penelitian ini dilakukan untuk mengetahui signifikansi pengaruh big five personality, coping stress dan variabel demografis terhadap post traumatic growth pada remaja yang kehilangan salah satu orangtua (yatim-piatu) di 5 yayasan panti asuhan sekitar DKI Jakarta. Subjek pada penelitian ini berjumlah 232 remaja yatim-piatu yang tinggal menetap di panti asuhan di daerah Jakarta, yang diambil dengan teknik nonprobability sampling yaitu purposive sampling. CFA (Confirmatory Factor Analysis) digunakan untuk menguji validitas alat ukur dan Multiple Regression Analysis digunakan untuk menguji hipotesis penelitian.Hasil penelitian menunjukkan bahwa ada pengaruh yang signifikan secara bersama-sama dari big five personality, coping stress dan variabel demografis (jenis kelamin) terhadap post traumatic growth pada remaja panti asuhan. Hasil uji hipotesis dari dimensi variabel big five personality menunjukkan bahwa tipe kepribadian openness memiliki pengaruh yang signifikan terhadap post traumatic growth. Hasil penelitian juga menunjukkan proporsi varians dari post traumatic growth yang dijelaskan oleh seluruh variabel independen adalah $9.2 \%$, sedangkan sisanya dipengaruhi oleh variabel lain diluar penelitian ini.
\end{abstract}

Kata Kunci: post traumatic growth, big five personality, coping stress, jenis kelamin, dan remaja

Diterima: 12 Januari 2017 Direvisi: 15 Februari 2017 Disetujui: 19 Maret 2017 


\section{PENDAHULUAN}

Masa remaja merupakan masa sebagai periode perubahan yang salah satunya adalah perubahan yang rentan akan keadaan meningginya emosi, yang intensitasnya bergantung pada tingkat perubahan fisik dan psikologis yang terjadi. Tak jarang dimasa remaja terkadang harus mampu menstabilitaskan keadaan emosi yang dialaminya terutama dalam keadaan yang dapat mengganggu perkembangan psikologisnya (Hurlock, 1980). Ada beberapa hal yang dapat mengakibatkan munculnya gangguan perkembangan psikologis di masa remaja khususnya dalam menerima perasaan tertekan, mengancam, terpukul, depresi, stres bahkan trauma. Tekanan itulah yang datang tidak hanya dari sekolah, keluarga dan orang tua tapi juga dari media, kelompok sebaya dan masyarakat secara keseluruhan, (Coleman, 1987; dalam Frydenberg, E. 1997).

Mitos - mitos yang dicurigai dari penelitian terdahulu tentang kekhawatiran pada remaja terhadap perasaan tertekan yang dapat dialami dan diterimanya, seperti yang mengklaim masa remaja sebagai periode badai dan stres yang tak terelakan, perubahan hormonal yang selalu menyebabkan kesulitan, dan ada kesenjangan generasi negatif antara remaja dan orang tua, (Petersen, 1993; dalam Frydenberg, E. 1997). Demikian pada penelitian Tedeschi dan Calhoun, (1996) menjelaskan macam - macar pengalaman yang mengakibatkan muncul trauma pada seseorang seperti mengalami peristiwa negatif, berkabung, terinfeksi HIV/AIDS, penyakit kanker, transplantasi sumsum tulang, serangan jantung, menghadapi masalah medis pada anak - anak, kecelakaan transportasi, rumah kebakaran, perceraian orang tua, kekerasan seksual dan pelecehan seksual, pertempuran, pengalaman pengungsi, dan lain-lain yang bisa menimbulkan traumarik pada diri individu yang mengalami.

Berdasarkan fenomena - fenomena tersebutlah peneliti tertarik menjadikan dasar untuk mengembangkan peristiwa yang dapat membuat remaja harus mampu menerima keadaan dan memperbaiki perkembangan psikologis yang dialaminya, khususnya pada salah satu fenomena seperti kehilangan orang yang dicintai dalam hal ini kehilangan salah satu orangtua. Pada saat seorang remaja dihadapkan pada suatu peristiwa yang tidak diinginkan dalam hidupnya, tentunya individu akan terasa berat menerimanya, seperti peristiwa kematian yang dapat memisahkan hubungan komunikasi antara individu dengan orang tua, peristiwa tersebut sulit untuk diterima oleh siapapun karena tidak ada satu orang pun yang benar-benar siap ketika harus kehilangan orang yang dicintainya. Karena dimasa remaja rentan dalam mengalami stres maupun depresi kerena menghadapi berbagai keadaan yang tertekan dalam dirinya dapat juga mempengaruhi beragam resiko yang mengancam perkembangan psikologis pada dirinya. Dikarenakan peristiwa kematian itu menimbulkan duka yang mendalam bagi remaja dan rasa duka itu menyebabkan munculnya penolakan, tidak mampu menerima kenyataan, perasaan bebas, putus asa, menangis, resah, marah, perasaan bersalah, merasa kehilangan, rindu, dan perasaan tidak rela. Masa itulah adalah masa yang sulit bagi seorang remaja untuk dapat menghadapi dan melewati keadaan tertekan terutama dalam peristiwa kematian orang tuanya.

Berdasarkan latar belakang yang telah dipaparkan, peneliti tertarik untuk melakukan penelitian lebih lanjut yang berkaitan dengan big five personality 
(extraversion, neurotisicm, agreeableness, conscientiousness, dan openness) coping stress (problem focused coping, emotion focused coping, dan maladaptive coping) dan variabel demografis yaitu jenis kelamin terhadap posttraumatic growth pada remaja yang mengalami keadaan traumatik dan berusaha untuk menangani keadaan yang dialaminya lebih positif dan menghasilkan perubahan pertumbuhan yang lebih baik pasca traumatik yang dialami. Sehingga peneliti memutuskan untuk memberi judul "pengaruh big five personality, coping stress dan variabel demografis terhadap post traumatic growth pada remaja".

\section{KAJIAN TEORI}

Fenomena kehilangan salah satu atau kedua orang tua inilah yang menjadi suatu fenomena yang traumatik dan memberikan efek kedukaan berpanjangan diri bagi remaja yang mengalami kejadian ini, namun bagi sebagian yang lain menjadi suatu proses kelanjutan diri untuk menjalani kehidupan di masa depan meskipun dengan keluarga yang tidak lagi utuh. Bahkan tidak jarang bagi remaja kehilangan salah satu orang tua akan menyisakan luka yang mendalam, mengalami shock dan sangat terpukul bagi remaja. Inilah awal keadaan atau peristiwa yang penuh tekanan bagi remaja tersebut yang dapat di artikan sebagai kejadian traumatik yang dapat memunculkan respon negatif pada seseorang remaja. Karena akan menimbulkan dampak serius dalam tahapan perkembangan bagi remaja dan peristiwa tersebutlah yang menjadikan seorang remaja harus untuk dapat melakukan suatu perubahan positif dan harus mampu mencari solusi dari perasaan yang dialaminya sebagai hasil kejadian traumatik tersebut. Perubahan positif itulah yang muncul dari hasil peristiwa hidup yang negatif, seperti penerapan prioritas baru, melakukan kemungkinan hal - hal yang baru dan memiliki pandangan yang lebih baik terhadap kehidupan.

Reaksi remaja terhadap kehilangan orang yang dicintai, khususnya kehilangan salah satu orang tua biasanya dapat menyebabkan perasaan kesedihan, kerinduan akan almarhum/almarhumah orang tua, dan keinginan untuk menunjukkan hal-hal yang berbeda. Reaksi tersebut yang biasanya dapat menyebabkan remaja mengalami emosi negatif, sulit untuk berpikir mencari solusi, dan sulit untuk menempatkan dirinya dalam melakukan perubahan perubahan yang lebih positif untuk dirinya dimasa depan. Hal tersebut tentu dapat menimbulkan tingkat stres yang tinggi, berbagai reaksi fisik maupun psikologis yang tidak menyenangkan, mengancam, dan mengganggu perasaan bisa dialami juga. Meskipun dalam kebanyakan keadaan individu menghadapi keadaan yang traumatik tidak mengembangkan gangguan kejiwaan, maka krisis traumatik yang di alami individu memang dapat meningkatkan resiko dalam mengembangkan masalah kejiwaan (Rubonis dan Bickman, 1991).

Segala reaksi individu khususnya remaja dalam menangani keadaan traumatik, keadaan mengancam, tidak menyenangkan, dan bahkan gangguan hal - hal yang menimbulkan emosi negatif dalam dirinya tentu di butuhkannya solusi dalam mengatasinya. Dan setiap individu memiliki kemampuan tersendiri dalam mengatasi dan melewati permasalahannya, bahkan terkadang berbeda dalam merespon suatu permasalahan yang dihadapi. Reaksi yang dimunculkan pun berbeda - beda dalam menangani suatu peristiwa yang dihadapkannya 
terlebih apabila mengalami peristiwa yang terjadi secara mendadak dan tiba tiba.

Hasil perubahan positif dari reaksi - reaksi negatif yang muncul pada perasaan individu yang mengalami trauma adalah pertumbuhan pasca trauma yang merupakan cara dalam menangani rasa traumatik dimana perubahan pertumbuhan tersebut penting untuk menjaga pemahaman bahwa keadaan traumatik dalam hidup biasanya menimbulkan reaksi psikologis yang menyenangkan. Pertumbuhan pasca trauma terjadi bersamaan dengan upaya untuk beradaptasi dengan emosi negatif dari keadaan yang dapat menimbulkan tingkat tinggi tekanan psikologis pada individu. Karena keadaan traumatik pada individu yang dapat menghasilkan pertumbuhan pasca trauma yang merupakan perubahan yang lebih positif dari keadaan traumatik. (Tedeschi dan Calhoun, 1996; dalam Pollard dan Paul, 2007) mengkategorikan manfaat yang dilaporkan oleh penderita trauma menjadi tiga kelompok besar; perubahan yang dirasakan dalam diri, mengubah rasa hubungan dengan orang lain dan filosofi kehidupan yang berubah. Yang pertama melibatkan perubahan selfperceived di kemandirian dan kekuatan emosional. Kedua, Tedeschi et al. (1998) menggambarkan sejumlah cara di mana orang melaporkan hubungan mereka dengan orang lain untuk ditingkatkan mengikuti trauma. Ketiga, banyak korban trauma tampaknya merasa bahwa penghargaan mereka hidup atau penilaian dari prioritas yang diubah oleh pengalaman penyakit dan trauma.

Perubahan - perubahan yang dihasilkan bersifat positif dan munculah posttraumatic growth yang dapat dialami oleh siapa saja termasuk remaja. Tedeshi dan Calhoun (2004) dikonsepkan dalam perubahan positif ini sebagai hasil dari berjuang dengan menantang krisis hidup sebagai "pertumbuhan pasca trauma". Kebanyakan model yang mencoba menjelaskan jenis pertumbuhan positif berhipotesis bahwa peristiwa stres dapat mengganggu sistem kepercayaan dasar individu dan pengolahan kognitif yang dihasilkan merupakan upaya untuk memahami bahwa peristiwa traumatik, (Affleck dan Tennen, 1996; dalam Tedeschi dan Calhoun, 2000). Sehingga posttraumatic growth yang dialami remaja tidak boleh dibiarkan berlarut - larut yang berkepanjangan karena dapat menimbulkan stres bahkan depresi sehingga remaja tidak dapat melanjutkan tugas perkembangannya terutama perkembangan emosional dan sosial mereka sehingga sedikit banyak memiliki adil dalam perilaku mereka. Oleh karena itu, pembahasan tentang posttraumatic growth pada remaja menarik untuk diteliti, karena dimasa remaja, seorang remaja membutuhkan kasih sayang, perhatian, dan kehangan dari orangtua, mereka akan bangga adanya seseorang yang mereka kagumi dalam kehidupannya seperti sosok orang tua, tetapi disaat itulah masa remajanya mereka kehilangan sosok yang mereka kagumi karena peristiwa kematian.

Perubahan positif tersebut dikenal sebagai istilah posttraumatic growth (Calhoun dan Tedeschi, 2004). Tedeschi dan Calhoun (1995) menggambarkan suatu fenomena yang mereka sebut 'pertumbuhan pasca-trauma' di mana individu mengadopsi pendekatan terhadap peristiwa traumatis yang memungkinkan mereka untuk memahami dan memperoleh manfaat seperti pertumbuhan pribadi dan pengembangan melalui proses berurusan dengan kesulitan mereka. Tedeschi, 
Park, dan Calhoun, 1998 (dalam Pollard dan Paul, 2007) berpendapat bahwa pertumbuhan pasca trauma dapat dilihat sebagai antitesis dari gangguan stres pasca-trauma seperti yang muncul berasal dari jenis yang sama dari peristiwa dan menegaskan bahwa pertumbuhan tersebut dapat transformatif dan dapat memiliki cakupannya mulai efek perilaku. Posttraumatic growth merujuk pada perubahan psikologis yang positif yang dialami sebagai hasil dari perjuangan dengan keadaan hidup yang sangat menantang. Seseorang yang melakukan perjuangan dalam menghadapi kejadian traumatik yang dengan jelas memberikan efek negatif pada kondisi psikologisnya ternyata dapat memberikan kebermaknaan pada dirinya. Posttraumatic growth terjadi pada orang-orang yang mengalami kejadian traumatik, misalnya pada individu yang mengalmai kebakaran dan kehilangan tempat tinggal, perceraian, keterbatasan fisik, kekerasan seksual, bencana alam, perang, kehilangan orang yang dicintai, atau diagnosis penyakit kronis (Linley dan Joseph, 2004). Dalam hal ini terdapat lima dimensi pada posttraumatic growth (PTG) yaitu appreciation of life, relating to others, personal strength, new possibilities, dan spiritual change.

Dalam posttraumatic growth remaja yang mengalami peristiwa traumatik harus dapat melakukan suatu perubahan positif dalam dirinya dengan melakukan lima domain dalam meningkatkan pertumbuhan pasca traumatiknya, yaitu dengan appreciation of life, dimana individu dapat memulai merefleksikan secara mendalam tentang kehidupan, kematian, spiritual, dan tujuan hidupnya. Relating to others, individu akan merasa lebih dekat dengan keluarga dan mengalami peningkatan dalam melakukan hubungan persahabtan dan menjalani kehidupan dengan lebih percaya diri. Personal strength, dimana individu mampu mengatasi trauma dan akan bangkit menjadi individu yang lebih kuat, percaya diri, terbuka, empati, kreatif, dewasa dan memiliki rasa kemanusiaan yang lebih tinggi. New possibilities, dimana apabila keinginan individu untuk merubah tujuan hidupnya dan menjadi individu yang fokus pada keadaan disini dan sekarang (here and now). Dan spiritual change, dimana individu lebih berpartisipasi dalam kegiatan kegiatan religiusitas dan lebih bersyukur dalam kehidupannya.

Posttraumatic growth (PTG) menurut Linely dan Joseph, (2004) mengatakan bahwa pertumbuhan pasca traumatik dapat membuat seseorang lebih memiliki kehidupan yang berarti. Namun posttraumatic growth (PTG) tidak hanya sekedar bebas, bahagia atau memiliki perasaan yang baik. Posttraumatic growth (PTG) juga membuat seseorang merasakan kehidupan yang level kedekatan secara personal, interpersonal dan spiritual yang lebih dalam.

Namun dalam posttraumatic growth tidak terjadi begitu saja setelah seseorang mengalami kejadian penuh tekanan. Seseorang tersebut haruslah melakukan perjuangan terhadap suatu kejadian yang penuh dengan tekanan tersebut. Kemampuan seseorang untuk mengubah dirinya menjadi posisif berkaitan dengan bagaimana seseorang tersebut mengalami suatu kesulitan yang dihadapinya. Dibutuhkan beberapa faktor internal maupun eksternal yang dapat mempengaruhi perkembangan posttraumatic growth seseorang.

Faktor yang mempengaruhi perkembangan posttraumatic growth pada penelitian ini adalah faktor kepribadian (Big five personality) dan cara mengatasi 
stres (coping stres). Dan faktor lainnya yang memperngaruhi posttraumatic growth adalah faktor demografiss seperti usia dan jenis kelamin.

Salah satu faktor internal yang mempengaruhi perkembangan posttraumatic growth adalah big five personality dan coping stres. Berdasarkan penelitian terdahulu Jane Shakespeare-Finch, Kathryn Gow, dan Sandy Smith (2005) melakukan penelitian untuk mengetahui hubungan big five personality pada posttraumatic growth, hasil yang diperoleh adalah bahwa big five personality berasosiasi secara positif terhadap posttraumatic growth hal ini dikarenakan proses posttraumatic growth muncul untuk memberikan waktu pada individu agar dapat melakukan proses perubahan positif yang tepat untuk menangani proses situasi dan penyesuaian keadaan seseorang setelah peristiwa traumatis yang dialaminya. Adapun dimensi dari big five personality yang terdiri dari: extraversion, neuroticism, agreeableness, conscientiousness dan openness. Hal tersebut didukung oleh pernyataan dari Magnus, Diener, Fujita, dan Pavot, 1993 (dalam Jane Shakespeare-Finch et, al 2005), menyatakan bahwa hasil dari big five personality dapat memberikan kesempatan untuk munculnya posttraumatic growth.

Pada penelitian Galea Michael (2014) melakukan penelitian pada big five personality terhadap posttraumatic growth, hasil yang diperoleh adalah bahwa big five personality berkorelasi positif dengan posttraumatic growth. Hal tersebut menunjukkan bahwa big five personality memberikan pengaruh yang positif dalam menangani stres yang di rasakan individu dalam pertumbuhan pasca trauma yang dialami. Sedangkan pada penelitian Blackie et, al. (2016) mengungkapkan bahwa dalam penelitian yang dilakukan adanya pengaruh big five personality tehadap posttraumatic growth. Hasil penelitian tersebut mengungkapkan hubungan perngaruh yang terdapat didalamnya sebagai bentuk individu harus menyadari keadaan stres yang dialami untuk dapat mengatasi secepatnya dan melaporkan perubahan - perubahan yang sudah dilakukan, agar keadaan stres yang dialami tidak berkepanjangan dalam melakukan posttraumatic growth. Dan pada penelitian Garnefski et, al (2008) menyebutkan dalam penelitiannya bahwa big five personality memberikan pengaruh terhadap posttraumatic growth, dilihat dari hasil penelitian yang diperoleh bahwa big five personality memiliki kontribusi besar pada nilai varians yang dihasilkan dalam perubahan posttraumatic growth.

Berdasarkan penelitian yang dilakukan oleh Tedeschi dan Calhoun, 1996 (Valerie A. dan Mary J. 2010), menyatakan bahwa coping stres merupakan faktor yang mempengaruhi posttraumatic growth secara kuat dalam mendukung perubahan positif untuk mengatasi keadaan traumatik pada seseorang. Valerie A. dan Mary J. (2010) mengatakan untuk memberikan penangan dan cara untuk mengatasi keadaan tertekan dan traumatis dapat memberikan perubahan yang positif pada posttraumatic growth bagi seorang remaja dan menemukan bahwa coping stres memiliki hubungan lebih kuat untuk mendukung perubahan dalam menangani keadaan traumatis pada seseorang terhadap posttraumatic growth pada dimensinya coping stres yang terdiri dari: problem focussed coping, emosional focussed coping, dan maladaptive coping. Hal ini terjadi karena dengan adanya perubahan positif, maka akan membuat individu berpikir lebih baik dalam menjalani hidup, menemukan kekuatan dalam pribadi dan mampu memaknai keadaan selama masa-masa sulit. 
Pada penelitian Bussell A, dan Mary, J. (2010) mengungkapkan adanya hubungan pengaruh coping stres terhadap posttraumatic growth dalam menangani keadaan masalah yang menyebab stres pada individu yang secara keseluhan hasil penelitian telah menunjukkan bahwa dari masing-masing dimensi di coping stres memberikan hubungan yang terkait pada penanganan positif pada keadaan stres. Sedangkan pada penelitian Schuettler dan Adriel, (2011) mengatakan ada hubungan coping terhadap posttraumatic growth, yang dijelaskan dalam hasil penelitiannya bahwa diprediksi memberikan perpektif secara positif dengan posttraumatic growth dalam menangani suatu peristiwa dan keadaan yang bersifat stres. Selanjutnya, faktor lainnya yang mempengaruhi perkembangan posttraumatic growth adalah faktor demografis seperti usia dan jenis kelamin. Tedeschi dan

Calhoun (1996) menyatakan bahwa perempuan mengalami posttraumatic growth lebih tinggi dibandingkan pada laki - laki. Pada penelitian Jane Shakespeare et, al. (2005), didapatkan hasil signifikan tingkat lebih tinggi pada posttraumatic growth adalah wanita dari pada laki- laki. Dan pada penelitian Swickert dan James (2009) mengatakan bahwa perempuan dan laki -laki memiliki cara dalam mengahadapi masalah lebih kepada perempuan, karena perempuan mampu diharapkan dan dapat meminta bantuan dengan orang lain lebih mudah dibandingkan laki - laki yang hanya menganggap kecewa dalam menerima masalah tersebut dan menandakan kelemahan. Sehingga hasil yang diperoleh bahwa perempuan lebih mungkin dibandingkan laki - laki untuk mencari bantuan orang lain ketika menghadapi peristiwa stres.

\section{METODE PENELITIAN}

\section{Populasi, sampel dan teknik pengambilan sampel}

Populasi dalam penelitian ini adalah remaja yatim-piatu yang bertempat tinggal menetap di panti asuhan yang berdomisili di wilayah DKI Jakarta. Sampel penelitan sebanyak 232 orang dengan rentang usia 16 - 18 tahun. Teknik sampling pada penelitian ini bersifat non probability sampling dengan metode purposive sampling yaitu teknik pengambilan sampel secara sengaja sesuai dengan persyaratan sampel atau kriteria yang telah ditentukan. Dimana peluang terpilihnya setiap responden anggota populasi tidak dapat dihitung.

\section{Instrumen penelitian}

Terdapat tiga alat ukur yang digunakan dalam penelitian ini, yaitu:

\section{Alat ukur posttraumatic growth}

posttraumatic growth diukur dengan menggunakan skala yang penulis susun sendiri berdasarkan dimensi alat ukur yang dikembangkan oleh Tedeschi dan Calhoun (2004) dalam posttraumatic growth inventory (PTGI). Skala posttraumatic growth ini terdiri dari 21 butir item dengan 5 dimensi. Respon jawaban untuk item ini menggunakan format skala likert enam poin, mulai dari 1 (Tidak pernah) sampai 6 (Sering). 
2. Alat ukur Big five personality

Untuk mengukur big five personality penulis menggunakan skala yang penulis susun sendiri berdasarkan dimensi yang dikembangkan oleh Costa dan McCrae (2009) dengan lima tipe kepribadian yaitu extraversion, neuroticism, agreeableness, conscientiousness, dan openness to experience. Sedangkan untuk alat ukur yang peneliti susun menggunakan Big Five Inventory (BFI) yang dikembangkan oleh John, dkk (1991) berisi 44 item dan respon jawaban untuk item ini menggunakan skala likert empat poin dengan rentangan 1 (Sangat Tidak Setuju) sampai 4 (Sangat Setuju).

\section{Alat ukur coping stress}

coping stress diukur dengan menggunakan kuesioner yang disusun oleh penulis dengan menggunakan aspek yang dikemukakan oleh Carver et.al. (1989) yang terdiri dari 28 item. Kuesioner coping stress ini mengunakan respon jawaban untuk alat ukur ini menggunakan skala likert empat poin dengan rentangan 1 (Sangat Tidak Setuju) sampai 4 (Sangat Setuju).

\section{HASIL PENELITIAN}

\section{Hasil Uji Hipotesis}

Perolehan nilai $\mathrm{R}$ square menunjukkan angka sebesar 0.092 atau 9.2\%. Artinya proporsi varians dari posttraumatic growth yang dijelaskan oleh big five personality (extraversion, neurotisicm, agreeableness, conscientiousness, openness), coping stres (problem focused coping, emotion focused coping, maladaptive coping) dan variabel demografis (jenis kelamin) dalam penelitian adalah sebesar $9.2 \%$ sedangkan $90.8 \%$ sisanya dipengaruhi oleh variabel lain di luar penelitian ini. Untuk lebih jelas dapat melihat tabel berikut :

Tabel 2

Analisis Regresi

\begin{tabular}{lllcl}
\hline Model & $R$ & $R^{2}$ & Adjusted $R^{2}$ & Std. Error of the Estimate \\
\hline 1 &, $303^{\text {a }}$ &, 092 &, 055 & 7,94255 \\
\hline
\end{tabular}

Penulis selanjutny menganalisa dampak dari seluruh independen variabel terhadap posttraumatic growth. Adapun hasil uji $\mathrm{T}$ dapat dilihat pada tabel berikut:

\section{Tabel 3}

Anova pengaruh keseluruhan IV terhadap DV

\begin{tabular}{clllll}
\hline Model & Sum of Squares & $d f$ & Mean Square & $F$ & Sig. \\
\hline Regression & 1420,336 & 9 & 157,815 & 2,502 &, $010^{\mathrm{b}}$ \\
1 Residual & 14004,668 & 222 & 63,084 & & \\
$\quad$ Total & 15425,004 & 231 & & & \\
\hline
\end{tabular}

Berdasarkan uji F pada tabel di atas dapat dilihat bahwa nilai p (Sig.) pada kolom paling kanan adalah sebesar $p=0.010$ dengan nilai Sig. $<0.05$. Maka 
hipotesis nihil yang menyatakan tidak ada pengaruh yang signifikan dari seluruh independen variabel terhadap posttraumatic growth ditolak. Artinya, ada pengaruh yang signifikan dari big five personality (extraversion, neurotisicm, agreeableness, conscientiousness, openness), coping stres (problem focused coping, emotion focused coping, maladaptive coping) dan variabel demografis (jenis kelamin) terhadap remaja yatimpiatu di panti asuhan sekitar DKI Jakarta. Kemudian terakhir peneliti melihat koefisien regresi. Adapun hasil koefisien regresi dapat dilihat pada tabel berikut:

\section{Tabel 4}

koefisien regresi

\begin{tabular}{llllll}
\hline & \multicolumn{4}{l}{ Unstandardized Coefficients } & \multicolumn{3}{l}{ Standardized Coefficients } & \\
Model & $B$ & Std. Error & Beta & $t$ & Sig. \\
\hline (Constant) & 61,564 & 9.745 & & 6.317 & .000 \\
Extraversion & -.132 & .077 & -.120 & -1.707 & .089 \\
Neurotisicm & -.024 & .078 & -.022 & -.314 & .754 \\
Agreeableness & .097 & .069 & .098 & 1.408 & .161 \\
Conscientiousness & -0.19 & .084 & -.018 & -.223 & .824 \\
Openness & -.217 & .073 & -.225 & -2.981 & .003 \\
Problem focused coping & -.006 & .077 & -.005 & -.072 & .942 \\
Emotions focused coping & -.043 & .073 & -.042 & -.588 & .557 \\
Maladaptif coping & .117 & .062 & .125 & 1.886 & .061 \\
Jenis kelamin & -34.428 & 1.108 & -021 & -.311 & .756 \\
\hline \multicolumn{1}{c}{ Signifikan } & & & & & \\
\hline
\end{tabular}

Signifikan atau tidaknya koefisien regresi yang dihasilkan, dapat dilihat melalui kolom Sig. (kolom keenam). Jika Sig. <0.05 maka koefisien regresi tersebut signifikan yang berarti variabel independen tersebut memiliki pengaruh yang signifikan terhadap terhadap posttraumatic growth. Kemudian berdasarkan tabel diatas juga dapat diketahui persamaan regresi posttraumatic growth, yaitu :

Posttraumatic growth $=61.564+9.745-0.132$ (extraversion) -0.24 (neurotisicm) + 0.97 (agreeableness) -0.19 (conscientiousness) -0.217 (openness) $^{*}-0.06$ (problem focused coping) -0.43 (emotions focused coping) +0.117 (maladaptive coping) -0.344 (jenis kelamin).

\section{Proporsi varians}

proporsi varian dari masing - masing independent variable terhadap post traumatic growth terdapat dua variabel yang secara signifikan memberikan sumbangan terhadap varians post traumatic growth, yaitu extraversion, dan openness.

1. Variabel extraversion: diperoleh nilai koefisien regresi sebesar -0.132 dengan Sig. sebesar 0.089 (Sig. >0.05). dengan demikian $\mathrm{H}_{01}$ yang menyatakan tidak ada pengaruh signifikan dari extraversion terhadap posttraumatic growth diterima. Artinya extraversion tidak memiliki pengaruh yang signifikan terhadap posttraumatic growth.

2. Variabel neuroticism : diperoleh nilai koefisien regresi sebesar -0.024 dengan Sig. sebesar 0.754 (Sig.>0.05). dengan demikian $\mathrm{H}_{02}$ yang menyatakan tidak ada pengaruh signifikan dari neurotisicm terhadap posttraumatic growth diterima. 
Artinya neurotisicm tidak memiliki pengaruh yang signifikan terhadap posttraumatic growth.

3. Variabel agreeableness : diperoleh nilai koefisien regresi sebesar 0.097 dengan Sig. sebesar 0.161 (Sig. >0.05). dengan demikian $\mathrm{H}_{03}$ yang menyatakan tidak ada pengaruh signifikan dari agreeableness terhadap posttraumatic growth diterima. Artinya agreeableness tidak memiliki pengaruh yang signifikan terhadap posttraumatic growth.

4. Variabel conscientiousness : diperoleh nilai koefisien regresi sebesar -0.019 dengan Sig. sebesar 0.824 (Sig.>0.05). dengan demikian $\mathrm{H}_{04}$ yang menyatakan ada pengaruh signifikan dari conscientiousness terhadap posttraumatic growth diterima. Artinya conscientiousness tidak memiliki pengaruh yang signifikan terhadap posttraumatic growth.

5. Variabel openness: diperoleh nilai koefisien regresi sebesar -0.217 dengan Sig. sebesar 0.003 (Sig.>0.05). dengan demikian H5 yang menyatakan tidak ada pengaruh signifikan dari openness terhadap posttraumatic growth diterima. Artinya openness memiliki pengaruh yang signifikan terhadap posttraumatic growth. Arah koefisien negatif menunjukkan bahwa semakin tinggi variabel openness maka akan semakin rendah posttraumatic growth.

6. Variabel problem focused coping: diperoleh nilai koefisien regresi sebesar -0.006 dengan Sig. sebesar 0.942 (Sig.>0.05). dengan demikian $\mathrm{H}_{06}$ yang menyatakan tidak ada pengaruh signifikan dari problem focused coping terhadap posttraumatic growth diterima. Artinya problem focused coping tidak memiliki pengaruh yang signifikan terhadap posttraumatic growth.

7. Variabel emotions focused coping: diperoleh nilai koefisien regresi sebesar -0.043 dengan Sig. sebesar 0.557 (Sig. $>0.05$ ). dengan demikian $\mathrm{H}_{07}$ yang menyatakan ada pengaruh signifikan dari emotions focused coping terhadap posttraumatic growth diterima. Artinya emotions focused coping tidak memiliki pengaruh yang signifikan terhadap posttraumatic growth.

8. Variabel maladaptive coping: diperoleh nilai koefisien regresi sebesar 0.117 dengan Sig. Sebesar 0.061 (Sig.>0.05). dengan demikian $\mathrm{H}_{08}$ yang menyatakan tidak ada pengaruh signifikan dari maladaptive coping terhadap posttraumatic growth diterima. Artinya maladaptive coping tidak memiliki pengaruh yang signifikan terhadap posttraumatic growth.

9. Variabel Jenis kelamin : diperoleh nilai koefisien regresi sebesar -0.344 dengan Sig. sebesar 0.756 (Sig.>0.05). dengan demikian $\mathrm{H}_{09}$ yang menyatakan ada pengaruh signifikan dari jenis kelamin terhadap posttraumatic growth diterima. Artinya jenis kelamin tidak memiliki pengaruh yang signifikan terhadap posttraumatic growth.

\section{KESIMPULAN DAN SARAN}

\section{Kesimpulan}

Berdasarkan hasil analisis uji multiple regression, maka dapat disimpulkan bahwa terdapat pengaruh secara bersama-sama dari variabel Big five personality (extraversion, neuroticism, agreeableness, conscientiousness, dan openess), coping stress (problem focused coping, emotion focused coping, dan maladaptive 
coping) dan variabel demografis yaitu jenis kelamin terhadap posttraumatic growth pada remaja yang mengalami kehilangan orangtua (yatim-piatu) di wilayah DKI Jakarta.

Namun jika dilihat dari signifikan atau tidaknya pengaruh koefisien regresi dari setiap dimensi indepeden variabel, ditemukan bahwa hanya terdapat satu independen variabel yang menghasilkan pengaruh koefisien regresi yang signifikan, yaitu openness dari variabel big five personality.

\section{Diskusi}

Pada penelitian ini ditemukan bahwa ada pengaruh namun tidak signifikan terhadap variabel problem focused coping dari variabel coping stress, variabel emotions focused coping dari variabel coping stress, variabel maladaptive coping dari variabel coping stress, terhadap posttraumatic growth pada remaja yang mengalami kehilangan salah satu orangtua (yatim-piatu). Terdapat pula ada pengaruh yang negatif dan signifikan dari tipe kepribadian openness terhadap posttraumatic growth artinya semakin rendah tipe kepribadian openness maka semakin tinggi posttraumatic growth. Hal ini sejalan dengan penelitian yang dilakukan oleh Tedeschi dan Calhoun (1996). Penelitian Tedeschi dan Calhoun menggunakan alat ukur tipe kepribadian openness yaitu big five inventory (BFI). Hasilnya menyatakan bahwa posttraumatic growth memiliki pengaruh yang positif dan memiliki nilai signifikan pada variabel openness dari variabel big five personality terhadap posttraumatic growth. Hal ini disebabkan, dengan tingginya tipe kepribadian openness pada seseorang akan memberikan kemampuan dalam memandang positif pada trauma yang dialaminya, hal ini akan tampak hubungan pada remaja.

Selain itu, menurut hasil penelitian yang dilakukan oleh Tedeschi dan Calhoun et, al. 2004 (dalam Zoellner, 2008). Penelitian Tedeschi dan Calhoun yang menemukan hubungan positif antara PTG dengan openness, hubungan openness terhadap posttraumatic growth memiliki kaitan yang lebih besar terhadap gagasan baru dalam menangani trauma, namun tidak dalam tingkat keparahan trauma yang lebih tinggi.

Dalam penelitian menurut Bleckie (2016) menemukan adanya dukungan dalam perubahan kepribadian yang positif antara openness (big five personality) terhadap posttraumatic growth dalam mengatasi tingkat laporan individu setiap mengalami trauma dalam sehari-hari. Namun, penelitian kecil yang telah dilakukan untuk mengeksplorasi antara faktor big five personality dan hasil pasca traumatik positif. Studi yang telah dilakukan terdapat konfirmasi peran faktor big five personality dalam memprediksi hasil yang positif.

Dalam penelitian menurut Tedeschi dan Calhoun 1996 (dalam Mirean, 2016) menemukan korelasi yang signifikan antara kepribadian dan ukuran keseluruhan PTG serta puluhan domain tertentu di dalam PTG. Hubungan antara pertumbuhan pasca trauma dan faktor kepribadian dalam memberikan hubungan yang lebih menguntungkan pada kesehatan mental, mungkin karena mereka mempengaruhi seberapa baik orang mengatasi berbagai jenis stres, seperti mengenai hubungan antara keterbukaan dan pertumbuhan pasca trauma, beberapa penelitian melaporkan korelasi yang positif dalam menangani keadaan 
stres pada individu menurut Zoellner (dalam Mirean, 2016). Sedangkan menurut Costa dan McCrea (1985) bahwa openness didefinisikan sebagai kecenderungan untuk tertarik dalam situasi baru dan pengalaman baru. Karena orang dengan tingkat openness yang tinggi memiliki kemampuan untuk mengembangkan perubahan daripada berusaha untuk melawan kondisi itu (Merecz et al. 2012).

Dalam penelitian menurut Tedeschi dan Calhoun 2004 (dalam Herdiani, 2016). Hasil penelitian ini sejalan dengan penelitian terdahulu yang dilakukan oleh Herdiani (2016) dengan menggunakan analisis regresi yang menyebutkan terdapat pengaruh secara signifikan dari tipe kepribadian openness terhadap terhadap posttraumatic growth. Hal ini dapat dikatakan bahwa orang yang mengetahui atau menyadari akibat dari apa yang individu lakukan, maka individu tersebut cenderung melakukan apa yang sesuai dengan keadaan pribadinya dan cenderung lebih bisa menyesuaikan perilaku sesuai dengan perasaan traumatik yang dirasakan. Sehingga individu tersebut lebih mudah untuk mengubah traumatik.

Pada penelitian ini, terdapat hal yang menarik lainya dalam penelitian ini adalah pada variabel coping stres. Dari ketiga dimensi yang ada yakni problem focused coping, emotion focused coping dan maladaptive coping ternyata ketiganya memberikan sumbangan proporsi varian yang cukup besar, bahkan yang terbesar adalah maladaptive coping, namun ketiganya tidak memiliki pengaruh yang signifikan terhadap posttraumatic growth. Hal ini memang terlihat kontras, karena jika kita melihat dari tabel deskripsi variabel maladaptive coping, terlihat adanya coping yang tinggi pada responden. Ditambah dengan sumbangan proporsi varian yang cukup besar namun tidak signifikan perngaruhnya secara statistik. Keadaan semacam ini sering terjadi dalam analisis statistik.

Selain itu, jika dilihat dari karakrteristik responden, rata-rata responden mempunyai tingkat coping stres yang tinggi, berpengaruh namun tidak signifikan. Karakteristik remaja panti asuhan pada dasarnya memiliki coping stress yang tinggi, namun pengalaman yang mereka hadapi, kejadian buruk yang mereka alami, persepsi yang di rasakan, akan membuat coping stress mampu mengatasi semua stres yang dialami, dan mampu menempuh kehidupan atau bersosialisasi dengan baik, baik untuk dirinya saat ini maupun untuk dimasa depannya. Coping stress pada remaja di panti asuhan dapat memberikan individu mampu beradaptasi dan berkehidupan yang lebih baik dalam menerima keadaan traumatik yang di alami.

Di dalam penelitian ini secara keseluruhan terdapat pengaruh yang signifikan yaitu variabel big five personality terhadap posttraumatic growth. Namun jika dilihat masing-masing dimensinya, hanya satu variabel yang signifikan mempengaruhi posttraumatic growth. Sumbangan varians dari masing-masing variabel cukup besar, namun tidak semuanya signifikan. Hal ini bisa terjadi karena responden mengalami kesulitan pada saat mengisi skala pada item sehingga jawaban menjadi kurang baik, kondisi subjek dengan latar belakang pendidikan dan pemahaman bahasa yang berbeda juga memungkinkan mempengaruhi hasil penelitian ini. 


\section{Saran}

Hasil penelitian menunjukan bahwa seluruh variabel independen memberikan sumbangan variabel varian sebesar $9.2 \%$ terhadap posttraumatic growth. Sedangkan $90.8 \%$ dipengaruhi ileh variabel lain. Oleh sebab itu disarankan kepada penelitian selanjutnya agar meneliti variabel psikologis lain yang mempengaruhi posttraumatic growth misalnya gander, dukungan sosial, optimisme, resilience, hardiness, dan faktor yang mempengaruhi lainnya. Kemudian pada penelitian selanjutnya juga disarankan untuk menggunakan alat ukur yang lebih sesuai, singkat dan sederhana agar mempermudah responden untuk memberikan jawaban.

\section{DAFTAR PUSTAKA}

Barskova, T., dan Oesterreich, R. (2009). Post-traumatic growth in people living with a serious medical condition and its relations to physical and mental health: a systematic review. Berlin: Germany. Disability and Rehabilitation, 2009; 31(21).

Blackie, E. R., et. al. (2016). Post-traumatic growth as positive personality change: developing a measure to assess within-person variability. USA:

Journal of Research in Personality.

http://dx.doi.org/10.1016/j.jrp.2016.04.001

Bussell A.V., dan Mary J. (2010). A Longitudinal Investigation of Coping and Posttraumatic Growth in Breast Cancer Survivor. USA: Journal of Psychosocial Ontology. Vol. 28, No.1, Hal: 61-78. DOI: 10.1080/07347330903438958

Carver, S., Scheier, F. Micheal., dan Weintraub, K. J. (1986). Coping with stress: Divergent Strategies of Optimists and Pessimists. Journal of Personality and Social Psychology, Vol. 51, No. 6, Hal: 1257-1264.

Carver, S., Scheier, F. Micheal., dan Weintraub, K. J. (1989). Assesing coping strategies: a theoretically based approach. Miami: Journal of Personality and Social Psychology. Vol. 56, No. 2, Hal: 267 - 283.

Carver, S, Charles., dan Smith Jennifer, C. (2010). Personality and Coping. Miami: Annu. Rev. Psychol. 2010. No. 61, Hal: 679-704. DOI: 10.1146/annurev.psych. 093008.100352

Davidson, C. G., John M. N., dan Ann M. K. (2006). Psikologi Abnormal, edisi ke Sembilan. Jakarta: PT. Raja Grafindo Persada.

Feist, J., dan Feist, J. G. (2010). Teori Kepribadian: jilid 2. Jakarta: Salemba Humanika. Edisi ke 7. (112-114).

Finch- Shakespeare, J., Gow, K., dan Smith, S. (2005). Personality, coping, and posttraumatic growth in emergency ambulance personnel. Traumatology, Vol. 11, No. 4.

Frydenberg, E. (1997). Adolescent Coping: Theoretical and research perspectives. London and New York: Routledge.

Galea, M., (2014). The relationship of personality, spiritualily and posttraumatic growth to subjective wellbeing. Malta: University of Malta.

Gernefski, N., Kraaij, V., dan Schroevers, J. M. (2008). Post- traumatic growth after a myocardial infarction: a matter of personality, psychological 
health, or cognitive coping. Amsterdam: Clin Psychol Med Setting (2008) 15: $270-277$.

Hurlock B. E. (1980). Psikologi Perkembangan: Suatu Pendekatan Sepanjang Rentang Kehidupan, Edisi kelima. Jakarta: Erlangga.

John, O. P., dan Srivastava, S. (1999). The Big-Five trait taxonomy: History, measurement, and theoretical perspectives. In L. A. Pervin dan O. P. John (Eds.), Handbook of personality: Theory and research (Vol. 2, pp. 102-138). New York: Guilford Press.

Joseph, S. (2009). Growth following Adversity: positive psychological

perspective on posttraumatic stres. UK: University of Nottingham.

Joseph, S., Murphy, D.,dan Regel, S. (2012). An affective - cognitive processing model of post- traumatic growth. UK: Clinical psychology and Psychotherapy.

Krohne, W. H. (2002). Stres and Coping Theories. Universitat Mainz Germany Lazarus, R. S. dan Folkman, S. (1984). Stres, Appraisal, and Coping. New York: Springer Publishing Company, Inc.

Lazarus, R. S., dan Lazarus, B. N. (1994). Passion and reason. New York: Oxford University Press.

Linley, P. A., dan Joseph, S. (2004). Positive change following trauma and adversity: A review. Journal of Traumatic Stress, Vol. 17, Hal: 11-21.

McCrae, R. R. (1990). Traits and trait names: how well is Openness represented in natural languages?. USA: European Journal of Personality, Vol. 4, Hal: 119-129.

McCrae, R. R. (2008). A note on some measures of profile agreement. Journal of Personality Assessment, 90, 105-109.

http://dx.doi.org/10.1080/00223890701845104

McCrae, R. R., dan Costa, P. T., Jr. (2008b). The five-factor theory of personality. In O. P. John, R. W. Robins, dan L. A. Pervin (Eds.), Handbook of personality: Theory and research (3rd ed., pp. 159-181). New York, NY: Guilford Press.

McCrae, R. R. (2009). Personality profiles of cultures: Patterns of ethos. European Journal of Personality, No. 23, Hal: 205-227. DOI: $10.1002 /$ per. 712

Mirean, C. (2016). The relationship between secondary traumatic stres and personal posttraumatic growth: personality factors as moderatos. New York: J Adult Dev.

Papalia, Old, dan Feldman (2009). Human Developmen: Perkembangan Manusia. Buku 2, edisi ke sepuluh. Jakarta: Salemba Humanika.

Papalia, Old dan Feldman (2011). Human Developmen: Psikologi Perkembangan. Bagian V s/d IX, edisi ke Sembilan. Jakarta: Salemba Humanika.

Pervin, A. L., Cervone, D., John, P. O. Psikologi kepribadian. Teori dan Penelitian. edisi kesembilan. Jakarta: Prenada media group. Hal: 259 280.

Peterson, C., Park, N., Pole, N., D'Andrea, W., dan Seligman, E. P. M., (2008). Strengths of Character and Posttraumatic growth. Journal of Traumatic Stres, Vol. 21, No. 2, April 2008, Pp. 214-217. 
Pollard, C., dan Kennedy, P., (2007). A longitudinal analysis of emotional impact, coping strategies and post-traumatic psychological growth following spinal cord injury: a 10- year review. UK: The British Psychological Society.

Rahayu, D. (2016). Posttraumatic growth korban kekerasan pada anak dan remaja. Samarinda: Universitas Mulawarman Samarinda. Skripsi.

Santrock, W. J. (2007). Perkembangan anak. Edisi kesebelas. Jilid 2. Jakarta: Penerbit Erlangga.(Hal: 18-24).

Sarafino, E. P., dan Smith, T. W. (2011). Health Psychology: Biopsychosocial Interactions. Seventh edition. Wiley: John Wiley dan Sons, Inc.

Scheuttler, D. dan Boals, A. (2011). The path to posttraumatic growth versus posttraumatic stres disorder: contributions of event centrality and coping. USA: University of North Texas.

Scrignaro, M., Bami, S., dan Margin, E. M. (2011). The Combined contribution of social support and coping strategies in predicting post-traumatic growth: a longitudinal study on cancer patients. Italy: Psycho-Ontology.

Shaw, A., Joseph, S., dan Linley, A.P. (2003). Religion, Spirituality, and posttraumatic growth: a systematic review. London: University of Warwick.

Swikert, R., dan Hittner, J. (2009). Social support coping mediates the relationship between gender and posttraumatic growth. USA: Journal of Health Psychology. Vol. 14(3), 387-393.

Tedeschi, G. R. dan Calhoun, G. L. (1996). The Posttraumatic growth inventory: measuring the positive legacy of trauma. London: Journal of Traumatic Stres, Vol. 9, No. 3.

Tedeschi, G. R. dan Calhoun, G. L. (1999). Trauma and growth: Processes and Outcomes. London: Mahwah, New jersy. Lawrence Erlbaum Assosiates, Publishers.

Tedeschi, G. R. dan Calhoun, G. L. (2000). A Correlation Test of the Relationship Between Posttraumatic Growth, Religion, and Cognitive Processing. Journal of Traumatic Stres, Vol. 13, No. 3, 2000.

Tedeschi, G. R. dan Calhoun, G. L. (2004). Posttraumatic Growth:Conceptual Foundations and Emperical Evidence. London: University of North Carolina Charlotte. Psychological Inquiry, 2004, Vol. 15, No.1, 1-18. DOI: 10.1207/s15327965pli1501_01

Tedeschi, G. R. dan Calhoun, G. L. (2006). The Faoundations of posttraumatic growth: an expanded framework. London: The University of North Carolina at Charlotte.

Taku K., Cann, A., Tedeschi, G. R. dan Calhoun, G. L. (2008). The factor structure of the posttraumatic growth inventory: a comparison of five models using confirmatory factor analysis. London: Journal of Traumatic Stres, Vol. 21, No. 2.

Zoellner, T., Rabe S., Karl A., dan Maercker A. (2008). Posttraumatic growth in accident survivors: Openness and optimism as predictors of its constructive of illuspry sides. Journal of Clinical Psychology, No. 64, 245 263. 